\title{
Assessing Global Exposure to Volcanic Sulfur Dioxide Emissions
}

\author{
S. MAIRET ${ }^{1 *}$, S.A. CARN ${ }^{1}$
}

${ }^{1}$ Michigan Tech, Houghton, MI 49931, US

(*sjmairet@mtu.edu)

Persistent sulfur dioxide $\left(\mathrm{SO}_{2}\right)$ emissions from passively degassing volcanoes are detrimental to human and environmental health, and can be a chronic, long-term hazard. However, quantitative information on potential exposure to volcanic $\mathrm{SO}_{2}$ (i.e., a volcanic gas 'hazard map') is currently unavailable for the vast majority of active volcanoes and hence is rarely factored into volcanic hazard assessments.

We are investigating the spatial relationships between volcanic $\mathrm{SO}_{2}$ emissions measured by the NASA/Aura Ozone Monitoring Instrument (OMI) and human population count on both a regional and global scale for the years 2005 to 2016 . Using custom tools within GIS software, we are merging several datasets including gridded annual mean $\mathrm{SO}_{2}$ column amounts derived from OMI, human population count interpolated from Gridded Population of the World v.4, the ASTER Global Digital Elevation Model (DEM) v.3, global planetary boundary layer height (PBL) data [1], and existing $\mathrm{SO}_{2}$ emissions inventories $[2,3]$ to create volcanic gas hazard maps. The goal is to analyze annual global maps to identify geographic areas with populations at risk for high $\mathrm{SO}_{2}$ exposure. We have also created regional maps to quantify and observe yearly changes in $\mathrm{SO}_{2}$ concentrations and population and draw conclusions about these relationships over time.

Preliminary results include a time series of volcanic gas hazard maps quantifying yearly averaged $\mathrm{SO}_{2}$ column amounts (Dobson Units, DU). A key component of this work is the conversion of satellite-derived total $\mathrm{SO}_{2}$ columns to potential ground-level $\mathrm{SO}_{2}$ concentrations (in $\mathrm{ppb}$ ) for various meteorological conditions (e.g., PBL height). This conversion enables comparisons between estimated $\mathrm{SO}_{2}$ concentrations, epidemiological studies regarding the deleterious effects of $\mathrm{SO}_{2}$ exposure on human populations and surrounding environments, and established air quality standards (e.g., EPA). Our overall goal is to establish and validate a methodology for the production of volcanic gas hazard maps.

[1] Engeln \& Teixeira (2013) Amer. Meteor. Society 26, 65756590. [2] Fioletov et al. (2016) Atmos. Chem. Phys. 16, $11497-$ 11519. [3] Carn et al. (2017) Sci. Rep. 7, 44095. 